\title{
Development of gelatin nanoparticles with biotinylated EGF conjugation for lung cancer targeting
}

\author{
Ching-Li Tseng ${ }^{\mathrm{a}}$, Tzu-Wei Wang ${ }^{\mathrm{a}}$, Guo-Chung Dong ${ }^{\mathrm{b}}$, Steven Yueh-Hsiu Wu ${ }^{\mathrm{a}}$, \\ Tai-Horng Young ${ }^{\mathrm{a}}$, Ming-Jium Shieh ${ }^{\mathrm{a}}$, Pei-Jen Lou ${ }^{\mathrm{c}}$, Feng-Huei Lin ${ }^{\mathrm{a}, *}$ \\ anstitute of Biomedical Engineering, National Taiwan University, No. 1, Sec. 1, Ren-ai Rd., Taipei City 100, Taiwan \\ ${ }^{\mathrm{b}}$ Department of Chemistry, National Chung-Hsing University, No. 250, Kuo Kuang Rd., Taichung City 402, Taiwan \\ ${ }^{\mathrm{c}}$ Department of Otolaryngology, National Taiwan University Hospital and National Taiwan University College of Medicine, \\ No. 7, Chung San South Road, Taipei City 100, Taiwan
}

Received 20 March 2007; accepted 9 May 2007

Available online 18 May 2007

\begin{abstract}
Since lung cancer is the most malignant cancer today, a specific drug-delivery system has been developed for superior outcome. In this study, gelatin nanoparticles (GPs) employed as native carriers were grafted with NeutrAvidin ${ }^{\text {FITC }}$ on the particle's surface (GP-Av). Next, the biotinylated epithelial growth factor (EGF) molecules were conjugated with NeutrAvidin ${ }^{\text {FITC }}$, forming a core-shell-like structure (GP-Av-bEGF) to achieve the enhancement of targeting efficiency. These nanoparticles were applied as an EGF receptor (EGFR)-seeking agent to detect lung adenocarcinoma.

The results showed that the modification process had no significant influence on particle size (220 nm) and zeta potential ( $-9.3 \mathrm{mV})$. By the in vitro cell culture test, GP-Av-bEGF resulted in higher entrance efficiency on adenocarcinoma cells (A549) than that on normal lung cells (HFL1) because A549 possessed greater amounts of EGFR. We also found that uptake of GP-Av-bEGF by A549 cells was time and dose dependent. Confocal microscopy confirmed the cellular internalization of GP-Av-bEGF, and more fluorescent spots of GP-Av-bEGF nanoparticles were obviously observed as well as lysosomal entrapment in A549. Finally, the delivery was demonstrated by in vivo aerosol administration to cancerous lung of the SCID mice model, and specific accumulation in cancerous lung was confirmed by image quantification. The targeting ability of GP-Av-bEGF was proved in vitro and in vivo, which holds promise for further anti-cancer drug applications.
\end{abstract}

(C) 2007 Elsevier Ltd. All rights reserved.

Keywords: Nanoparticle; Gelatin; Surface modification; Drug delivery; Lung

\section{Introduction}

Lung cancer is the most harmful cancer today and the mortality rate is extremely high in both primary and metastases neoplasia [1]. The prognosis of lung cancer treated with conventional treatments such as chemotherapy is still far from satisfactory, because the non-specific

\footnotetext{
${ }^{*}$ Corresponding author. Tel.: + $886223123456 x 1568$; fax: +886223940049 .

E-mail address: double@ntu.edu.tw (F.-H. Lin).
}

reactions of anti-tumor agents still contribute to high levels of toxicity to healthy tissues and damage normal cells [2].

For the reduction of side effects, specific drug delivery systems (DDSs) have been investigated in these decades. Encapsulated anti-cancer drugs in nanoparticles can protect not only the integrity of drugs during their transport in blood circulation but also the normal nontargeting tissues from the toxicity [3]. The purpose of reducing the delivery drugs to unwanted sites could be achieved by using a controlled drug carrier system with good targeting ability [4]. To enhance the targeting efficiency of nanoparticles to specific cells or tissues, 
specific ligands were often conjugated to the surface of nanoparticles for active targeting. Antibody-coupled liposomes (immunoliposomes) were first described in the early 1980s [5]. However, fundamental problems regarding the preparation and application of immunoliposomes, such as their stability and pharmacokinetics, are still an unsolved problem [6]. Among several coupled homing systems, ligand-coupled nanoparticles were regarded as a very attractive drug-targeting system as they were highly specific to target cells and able to accommodate drugs [7].

Furthermore, with the higher porosity of the tumor vasculature and the lack of lymphatic drainage, the enhanced permeability and retention (EPR) effect permit nanoparticles more easily to be entrapped in most solid tumors [8]. When the biopolymer carrier is engrafted with particular ligands such as epithelial growth factor (EGF) [9], it can be employed for more specific recognition and interaction with cancer cells because of the overexpression of EGF receptor (EGFR) on human tumors, especially on non-small-cell lung cancer [10]. In the present study, EGF-conjugated gelatin nanoparticles (GPs) are used as a targeting vehicle to detect lung adenocarcinoma cells.

Several polymers, of natural as well as synthetic origin, have been used for the preparation of nanoparticles. Gelatin was selected as the raw material to form nanoparticles because of its biocompatibility and biodegradability [11]. Furthermore, the many functional groups on gelatin, including carboxyl and amine groups, make it an ideal candidate for surface modification to conjugate with cancer-selective molecules. Polymeric nanoparticles surface binding with avidin offers the opportunity of attaching a multitude of biotinylated ligands to it [12]. The development of a cell-specific drug carrier system on the basis of GPs conjugated with avidin could provide the potential benefit that there are four binding sites on avidin with biotin molecules [13]. Four types of biotinylated ligands or four times of the same biotinylated molecular could form a complex with the GPs via avidin to achieve specific and receptor-mediated cellular uptake.

The objective of the present work was to develop a cellspecific drug carrier on the basis of GPs. Biotinylated EGF was coupled to the particle surface via avidin to achieve EGF receptor-mediated endocytosis into lung cancer cells. To improve the targeting effectiveness of conjugated EGF, surface modification with avidin was carried out as previously described [14]. In vitro and in vivo cellular uptake and distribution of GPs modified with or without EGF were examined by flow cytometry and confocal microscopy. The in vivo targeting capacity was investigated by aerosol delivery to the severe combined immunodeficiency (SCID) mice.

\section{Materials and methods}

\subsection{Reagents and chemicals}

Gelatin type A (derived from porcine skin, bloom 175), 5,5'-dithiobis(2-nitrobenzoic acid) (DTNB), Hams' F12k medium, RPMI1640 medium, $N$-2-hydroxyethylpiperazine- $N^{\prime}$-2-ethane sulfonic acid (HEPES), bicinchoninic acid (BCA) protein assay kit, ethylenedinitrilotetraacetic acid (EDTA) and 1-(4,5-dimethylthiazol-2-yl)-3,5-diphenylformazan (MTT) were purchased from Sigma (USA). NeutrAvidin ${ }^{\text {TM }}$, fluoresceinconjugated (NeutrAvidin ${ }^{\text {FITC }}$, $m$-maleimidobenzoyl- $N$-hydroxysulfosuccinimide ester (Sulfo-MBS), Sulfo-NHS-LC-biotin, 2-iminothiolane $\mathrm{HCl}$, $\mathrm{D}^{- \text {salt }^{\mathrm{TM}}}$ dextran desalting columns and $\mathrm{EZ}^{\mathrm{TM}}$ Biotin Quantization Kit were purchased from Pierce (USA). Human-recombinant EGF and mouse (monoclonal) anti-human EGF receptor antibody (EGFR MAb) were obtained from BioSource (USA). 4',6-Diamidino-2-phenylindole, dihydrochloride (DAPI) and LysoTracker Red were purchased from Molecular Probes (USA). The Amicon ${ }^{\circledR}$ ultra-centrifugal filter device was from Millipore (USA). Fetal calf serum (FCS) was from Biological Industrial Inc. Trypsin-EDTA, penicillin/streptomycin and phosphatebuffered saline (PBS) were obtained from Gibco (USA). All other chemicals were from Sigma-Aldrich in analytical grade.

\subsection{Preparation of $G P S$}

GPs were prepared by the desolvation method as described previously [15]. In brief, $5 \mathrm{ml}$ of $5 \%(\mathrm{w} / \mathrm{v})$ gelatin aqueous solution was heated to $50{ }^{\circ} \mathrm{C}$ followed by the addition of $5 \mathrm{ml}$ of acetone. The supernatant was discarded, and the precipitate was dissolved in hot water. The $\mathrm{pH}$ value was adjusted to 2.5 , and then $12 \mathrm{ml}$ acetone was added in the gelatin solution. The nanoparticles were cross-linked by glutaraldehyde and stirred at $1000 \mathrm{rpm}$ overnight. Finally, acetone was removed by vacuum drying, and the fabricated GPs were purified and resuspended in deionized water. These particles were stored at $4{ }^{\circ} \mathrm{C}$ for further applications.

\subsection{Surface modification of GPS}

\subsubsection{Neutr Avidin ${ }^{\text {FITC }}$ conjugated on the GP surface}

For thiolation, the solvent of GPs was dialyzed from water to sodium phosphate buffer with $10 \mathrm{~mm}$ EDTA (pH 8.0). Then, $1 \mathrm{ml}$ of GP solution $(8 \mathrm{mg} / \mathrm{ml})$ was reacted with 2 -iminothiolane $(28 \mathrm{~mm})$ for $1 \mathrm{~h}$ at $37^{\circ} \mathrm{C}$. These particles were purified by centrifugation with Amicon Ultra-4 filter devices (Mw cutoff, 30,000). The introduced sulfhydryl groups were determined by a spectrophotometer with the DTNB method. The NeutrAavidin ${ }^{\text {FITC }}$ was dissolved in sodium phosphate buffer ( $\mathrm{pH}$ 7.2) with by the addition of $2 \mathrm{mg}$ of Sulfo-MBS, mixed thoroughly and allowed to react at room temperature for $1 \mathrm{~h}$ [14]. The activated NeutrAvidin ${ }^{\text {FITC }}$ was purified by a gel filtration column. Then, an aliquot of the activated NeutrAvidin ${ }^{\text {FITC }}$ solution was mixed with the thiolated nanoparticles and reacted overnight at $4{ }^{\circ} \mathrm{C}$. The unbound NeutrAvidin ${ }^{\mathrm{FITC}}$ derivative was separated and

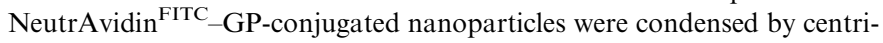
fugation with a centrifugal filter device (Mw cutoff, 100,000). The complex of NeutrAvidin ${ }^{\text {FITC }}$ GPs has been abbreviated to GP-Av in this study.

\subsubsection{Biotinylation of EGF}

EGF was dissolved in PBS ( $\mathrm{pH} 7.0$ ). The molar ratio in the reaction mixture of biotinylation reagent (Sulfo-NHS-LC-biotin) to EGF was 15:1 [14]. The reaction was stirred at room temperature for $30 \mathrm{~min}$. Biotinylated protein was separated from low molecular weight compounds by size exclusion chromatography through a D-salt dextran desalting column. The protein containing elute fractions was pooled, and the protein concentration was measured by the BCA protein assay kit. The ratio of biotin/EGF was determined by the $\mathrm{EZ}^{\mathrm{TM}}$ Biotin Quantization Kit. Biotinylated EGF has been abbreviated to bEGF in this study.

\subsection{3. bEGF binding to NeutrAvidin ${ }^{\text {FITC }}$ GPS}

About $500 \mu \mathrm{l}(4 \mathrm{mg} / \mathrm{ml})$ of $\mathrm{GP}-\mathrm{Av}$ nanoparticles and $250 \mu \mathrm{l}$ of biotinylated EGF $(300 \mu \mathrm{g} / \mathrm{ml})$ were mixed together and incubated at $4{ }^{\circ} \mathrm{C}$ for $2 \mathrm{~h}$. Afterwards the nanoparticles were purified by repeated centrifugation and redispersion in PBS. GP-Av-bEGF is the abbreviation that represents these multi-modified particles. 


\subsection{Characterization of GPS}

The particle size of GPs was determined by photon correlation spectroscopy using an N4 Plus Submicron Particles Sizer (Beckman Coulter, CA, USA). For particle size analysis, measurements were carried out at $25^{\circ} \mathrm{C}$ at a light-scattering angle of $90^{\circ}$. The mean particle size and polydispersity index were recorded. The surface charge of the nanoparticles was analyzed by Zetasizer, model HSA 3000 (Malvern, Worcestershire, England). For the zeta potential determination, PBS was used. Morphology of particles was observed by a transmission electron microscope (TEM, Hitachi H-7500, Japan).

\subsection{Cell culture}

Human lung cells of A549 (adenocarcinoma cells) and HFL1 (normal fibroblast cells) were grown in Ham's F12K medium, and H520 (squamous cell carcinoma) was cultured in RPMI-1640 medium supplemented with sodium pyruvate, glucose and HEPES. All culture media were supplemented with $10 \%$ FCS, $1 \%$ penicillin/streptomycin and $1.5 \mathrm{~g} / \mathrm{L}$ sodium bicarbonate. All cultures were maintained in an atmosphere of $5 \% \mathrm{CO}_{2}$ and $95 \%$ air at $37^{\circ} \mathrm{C}$. When they reached confluence, they were detached with $0.25 \%$ trypsin-EDTA and replated in a $10 \mathrm{~cm}$ culture dish in regular growth medium to allow for expansion.

\subsection{Cytotoxicity analysis}

The biocompatibility of modified GPs with HFL1 cells was tested using the MTT assay. HFL1 cells were cultured in a 96-well plate at an initial seeding density of $3 \times 10^{3}$ cells per well. After $24 \mathrm{~h}$, the growth medium was removed and replaced with fresh medium. Various concentrations of GP, GP-Av and GP-Av-bEGF were adjusted and added. Samples were incubated at $37^{\circ} \mathrm{C}$ for $24 \mathrm{~h}$, and then the supernatant was removed. Thereafter, cells were subjected to the MTT analysis. The optic density was measured at $470 \mathrm{~nm}$ on a microplate reader (SpectraMax M2, Molecular Device, USA). For proliferation assay, cells treated with modified nanoparticles were allowed to grow in culture medium and analyzed by MTT at 1, 3 and 7 days. The percentage of cell viability was illustrated as the ratio of absorbance of nanoparticle-treated cells relative to those untreated.

\subsection{Determination of cellular uptake by a flow cytometer}

A549, HFL1 and H520 cells were seeded in a T-25 flask and grown to $80 \%$ confluence; they were then treated with modified as well as unmodified nanoparticles at a particle concentration of $100 \mu \mathrm{g} / \mathrm{ml}$. After incubation for $3 \mathrm{~h}$, cells were washed twice with PBS, trypsinized, centrifuged and resuspended in PBS buffer. Analysis of particle uptake was acquired with a Becton Dickinson, FACScan flow cytometer system (Becton Dickinson, USA). The amount of EGF receptor (EGFR) on different cells was also stained by indirect immunofluorescence assay via EGFR MAb and analyzed by a flow cytometer.

\subsection{Cellular distribution in GPs}

Cellular distribution was performed in A549 cells. Approximately $4 \times 10^{5}$ cells were seeded in a 6-well plate per well with a cover slide to allow cell attachment overnight. Cells were treated with $100 \mu \mathrm{g} / \mathrm{ml}$ of either GP-Av or GP-Av-bEGF at $37^{\circ} \mathrm{C}$ for $3 \mathrm{~h}$. At the time point, cells were washed twice with PBS containing $2 \%$ FCS followed by staining with $75 \mathrm{nM}$ LysoTracker Red for a further $30 \mathrm{~min}$ at $37^{\circ} \mathrm{C}$. After that, cells were observed by a confocal microscope (Leica TCS SP2 Spectral Confocal System, Germany). For the nuclear stain, cells were washed with PBS and fixed with paraformaldehyde solution (3.7\% in PBS) for $30 \mathrm{~min}$ at room temperature. The paraformaldehyde solution was removed by washing three times with PBS. Afterward, $0.2 \%$ Triton X-100 was added for 5 min and the nucleus was stained with $300 \mathrm{~nm}$ DAPI solution followed by washing with PBS several times. The coverslips (cells side down) were mounted in mounting medium and sealed. Then cell samples were also examined by a confocal microscope.

\subsection{In vivo lung targeting}

CB-17/lcrCrl-scid-bg mice (SCID, 4 weeks old, $20 \mathrm{~g}$ body weight) were purchased from the Laboratory Animals Center, National Taiwan University, and maintained under specific pathogen-free conditions. To induce pulmonary metastases, A549 cells $\left(1 \times 10^{6}\right.$, in $100 \mu \mathrm{l}$ PBS $)$ were injected in male CB-17/lcrCrl-scid-bg mice via the tail vein [16]. After 1 month, mice with or without tumor inoculation were exposed to the aerosol. A nebulizer (AP-100100, APEX Medical Corp., Taiwan) was used to generate aerosol particles $(0.5-3 \mu \mathrm{m})$. A $5 \mathrm{ml}$ volume of GP-Av-bEGF nanoparticle solution in the reservoir of the nebulizer was consumed totally within $30 \mathrm{~min}$, and the total deposition dose during this inhalation period of GP-Av-bEGF was $5 \mu \mathrm{g} / \mathrm{g}$ per mice. After exposure, the mice were sacrificed at different time points $(0.5,1,24 \mathrm{~h})$. The tissues of the lung were examined by an image system (Xenogen IVIS $^{\circledR}$ Imaging System 50, USA).

\section{Results}

In the present study, gelatin-based nanoparticles with a specific ligand on the surface for tumor targeting were successfully developed as DDS. The probable mechanism is briefly described as follows. Basically, amino groups on the surface of GPs were used for a thiolation reaction with 2 -iminothiolane. The NeutrAvidin ${ }^{\text {FITC }}$ was then activated by Sulfo-MBS to form a covalent bond to the sulfhydryl groups on the surface of the gelatin nanoparticles (GP-Av). On the other hand, EGF was conjugated with Sulfo-NHS-LC-biotin. This biotinylated EGF (bEGF) was reacted with the previous GP-Av nanoparticles to form an avidin-biotin complex (GP-Av-bEGF) as shown in Fig. 1.

\subsection{Characterization of GPS}

The mean diameter of unmodified GPs was approximately $220 \mathrm{~nm}$ as measured by photon correlation spectroscopy Fig. 2(a)). The morphology was revealed as a spherical structure by TEM observation (Fig. 2(b)). All these particles

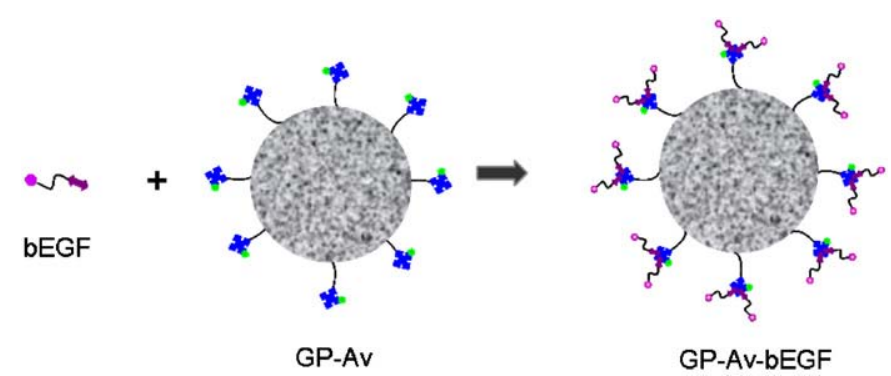

Fig. 1. Schematic drawing of the ligand-modified gelatin nanoparticles. The gelatin nanoparticles conjugated with NeutrAvidin ${ }^{\text {FITC }}$-biotinylated EGF were developed by biotinylated EGF (bEGF) attached to the surface of gelatin nanoparticles with NeutrAvidin ${ }^{\text {FITC }}$ via the affinity of avidin-biotin reaction. GP: gelatin nanoparticles, GP-Av: GP surface modified with NeutrAvidin ${ }^{\text {FITC }}$, GP-Av-bEGF: GP-Av conjugated with biotinylated EGF. 

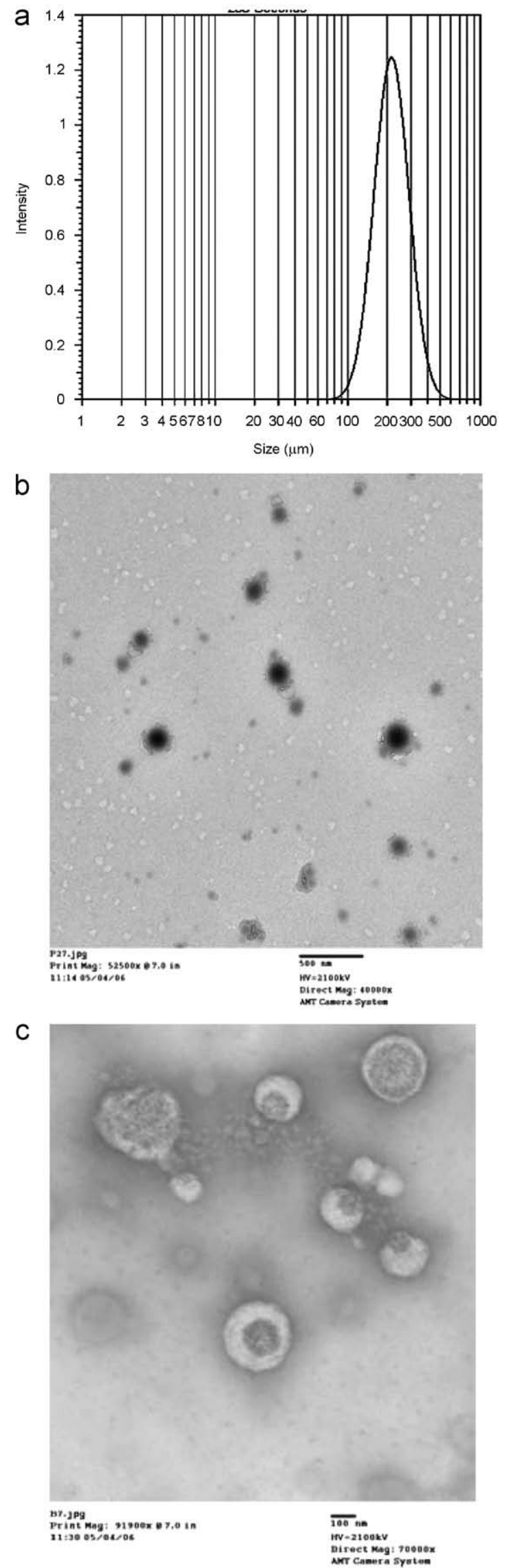

were very stable for 1 month without aggregation, and could be preserved for 3 months at $4{ }^{\circ} \mathrm{C}$ (data not shown). The particle size of GP, GP-Av and GP-Av-bEGF was $228.3 \pm 71.0,227.9 \pm 26.0$ and $241.9 \pm 34.5 \mathrm{~nm}$, respectively (Table 1). The zeta potential of particles at different stages is also demonstrated in Table 1. All measured zeta potential values of these samples were slightly negative. The average zeta potential value of GP, GP-Av and GP-Av-EGF was $-9.3 \pm 4.5,-9.4 \pm 1.6$ and $-8.5 \pm 0.8 \mathrm{mV}$, respectively. There was no significant difference of the zeta potential value between modified and unmodified GPs. From the image of TEM, the core-shell structure of the GP-Av-bEGF carrier was clearly observed, in which the GPs in the central part were enveloped by the avidin-biotin complex on the outer side as shown in Fig. 2(c). The image of the multilayered nanoparticles represents a uniform carrier system.

\subsection{Cytotoxicity assays}

The biocompatibility of modified and unmodified GPs with HFL1 cells was tested using MTT assay. As shown in Fig. 3, cells incubated with GP, GP-Av and GP-Av-bEGF remained nearly $100 \%$ viable when compared to the control group at concentrations as high as $1 \mathrm{mg} / \mathrm{ml}$. The cell viability was $94 \%, 91 \%$ and $96 \%$, for GP, GP-Av and GP-Av-bEGF-treated cells at $0.5 \mathrm{mg} / \mathrm{ml}$ concentration, respectively. No significant evidence of cytotoxicity was observed at day 3 after treatment (Fig. 3(a)), nor was the cell proliferation inhibited with nanoparticles for the indicated time (Fig. 3(b)). These data indicated that GPs with a varied degree of modification were biocompatible and non-toxic to normal lung fibroblast cells (HFL1).

\subsection{Nanoparticle accumulation in specific cells}

The accumulation of nanoparticles into different cells was investigated by tracking fluorescence-labeled nanoparticles (caused by NeutrAvidin ${ }^{\text {FITC }}$ ) using a flow cytometer. A549 (adenocarcinoma cells), HFL1 (normal lung fibroblast) and H520 (lung sequencema cell) were characterized by their EGF receptor expression level. Quantification of the EGFR was also determined by a flow cytometer using anti-EGFR MAb (Table 2). The result revealed that A549 cells showed a high expression of EGFR, while HFL1 cells showed a moderate expression and H520 cells showed nearly no expression of EGFR.

To be as effective as DDS, ligand-modified nanoparticles have to bind to specific cancer cells. The targeting ability of EGF-modified gelatin nanoparticles (GP-Av-bEGF) is illustrated in Fig. 4. After incubation of GP-Av-bEGF with cells for $3 \mathrm{~h}$, the highest binding capacity was observed

Fig. 2. Characterization of gelatin nanoparticles: (a) particle size was $228.3 \pm 71.0 \mathrm{~nm}($ mean \pm SD) of unmodified gelatin nanoparticles; (b) part of the sphere-liked gelatin nanoparticles were under $250 \mathrm{~nm}$ examined and (c) core-shell structure of GP-Av-bEGF was observed by transmission electron microscopy. 
Table 1

Size and zeta potential of gelatin nanoparticles with and without modification

\begin{tabular}{llll}
\hline Particles & Size $(\mathrm{nm})$ & Zeta $(\mathrm{mV})$ & P.I. \\
\hline GP & $228.3 \pm 71.0$ & $-9.3 \pm 4.5$ & 0.287 \\
GP-Av & $227.9 \pm 26.0$ & $-9.4 \pm 1.6$ & 0.366 \\
GP-Av-bEGF & $241.9 \pm 34.5$ & $-8.5 \pm 0.8$ & 0.489 \\
\hline
\end{tabular}

GP: gelatin nanoparticles; GP-Av: GP modified with NeutrAvidin ${ }^{\text {FITC }}$; GP-Av-bEGF: GP-Av conjugated with biotinylated EGF; P.I.: polydispersity index.
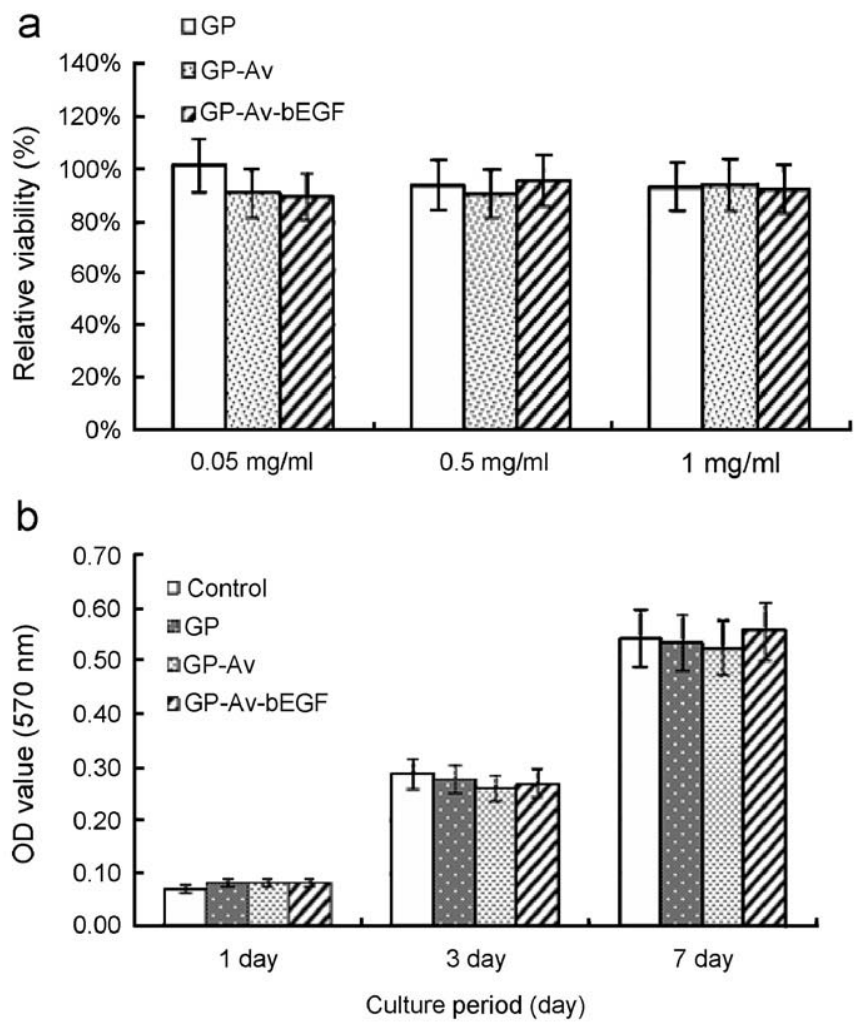

Fig. 3. Cytotoxicity of GP, GP-Av and GP-Av-bEGF in HFL1 cells: (a) incubated in different concentrations: $1 \mathrm{mg} / \mathrm{ml}, 0.5 \mathrm{mg} / \mathrm{ml}$, and $0.05 \mathrm{mg} / \mathrm{ml}$ for 3 days and (b) viability of cells at variant time point (particles concentration: $100 \mu \mathrm{g} / \mathrm{ml}$ ). The values represent mean $\pm \mathrm{SE}, n=6$.

in A549 cells (81\%), while it was less distinctive in HFL1 cells $(55 \%)$ and in H520 cells $(40.8 \%)$. The data were in agreement with the previous result, in which A549 had the highest density of EGFR compared to the other two kinds of cells. A distinct entrance rate of EGF-grafted GP-Av-bEGF particles was observed in A549, while there was no difference in cellular uptake including A549, HFL1 and H520 when cultured with no EGF-grafted GP-Av particles.

The influence of particle concentration ranging from 5.0 to $200 \mu \mathrm{g} / \mathrm{ml}$ was studied in Fig. 5(a). At a concentration of $200 \mu \mathrm{g} / \mathrm{ml}$, the uptake rate was up to $91 \%$ when A549 cells were treated with GP-Av-bEGF. On the other hand, the uptake rate was about $49 \%$ when treated with GP-Av. The cell uptake rate in both GP-Av-bEGF and GP-Av particles was dose dependent. Fig. 5(b) showed that the entrance rate of particles was directly proportional to the incubation time.

It is reported that endocytotic pathways are energy dependent and exhibit an optimum at a temperature of $37^{\circ} \mathrm{C}$ [17]. Lowering the temperature down to $4{ }^{\circ} \mathrm{C}$ would therefore result in strong inhibition of the endocytotic uptake efficiency. Our result from flow cytometric analysis showed that both GP-Av-bEGF and GP-Av nanoparticles incubated at $37^{\circ} \mathrm{C}$ could produce an increased FL1 signal in A549 cells at the tested concentrations $(100 \mu \mathrm{g} / \mathrm{ml})$. A substantial inhibitory effect on internalization of particles was observed in cell samples when cultivated at $4{ }^{\circ} \mathrm{C}$ (Fig. 6(a)). To distinguish the influence of EGF receptormediated endocytosis, cells preincubated with EGF $(50 \mu \mathrm{g} / \mathrm{ml})$ did have an effect on the internalization of nanoparticles. The initial uptake rate of A549 cells was $92 \%$, while it decreased to $65 \%$ after preincubation with EGF (Fig. 6(b)).

\subsection{Intracellular tracking of nanoparticles}

Particle internalization was further examined and visualized by confocal microscopy. After incubation for $3 \mathrm{~h}$, the intracellular fluorescence spots were clearly observed in cultured A549 cells in the presence of FITCconjugated GP-Av or GP-Av-bEGF particles $(100 \mu \mathrm{g} / \mathrm{mL})$ (Fig. 7(a) and (b)). The sections produced by the confocal microscopes showed that both GPs with or without EGF modification were incorporated into A549 cells, but cells treated with GP-Av-bEGF still expressed in higher amounts and also showed more homogeneous distribution in the cytoplasm (Fig. 7(b)). It is also known that EGF undergoes receptor-mediated endocytosis, which mediates the ligand-receptor complex inside the cell [9]. After incubation, nanoparticle uptake by A549 cells were deposited in the cytoplasm region with green fluorescence (Fig. 7(c)), and the cytoplasm of A549 cells was stained with red fluorescence by Lysotracker (Fig. 7(d)). The GP-Av-EGF nanoparticles and A549 cells were further co-localized indicating yellow spots (Fig. 7(e)), which revealed that GP-Av-EGF proceeds to the endo-lysosomal stage.

\subsection{In vivo targeting of $G P-A v-b E G F$ nanoparticles}

To confirm that ligand-modified nanoparticles could sufficiently target the specific organ in the complex 
Table 2

EGFR expression level in different cell lines

\begin{tabular}{lc}
\hline Cell line & EGFR expression (\%) \\
\hline H520 & 2.1 \\
HFL1 & 34.2 \\
A549 & 92.4 \\
\hline
\end{tabular}

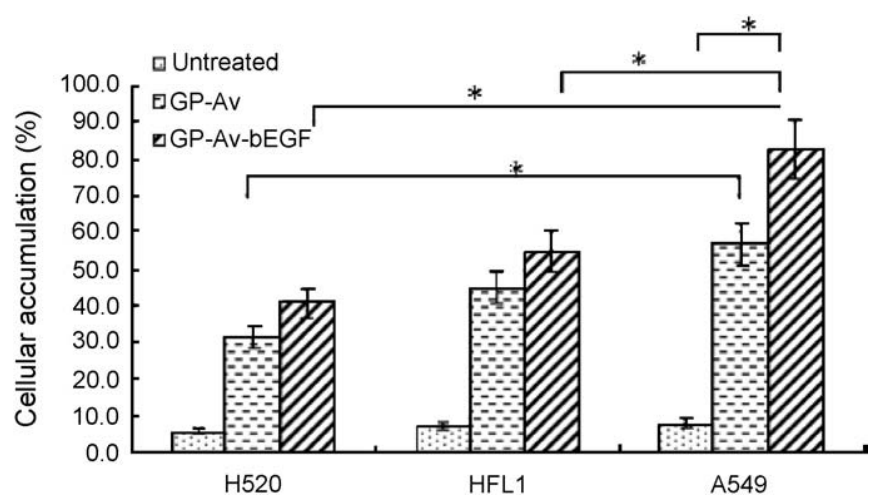

Fig. 4. Specificity of nanoparticles binding to EGFR expressing cells: H520, HFL1 and A549 cells were incubated with GP-Av or GP-AvbEGF nanoparticles for $3 \mathrm{~h}$ with particles concentration at $100 \mu \mathrm{g} / \mathrm{ml}$. The values represent mean \pm SE, $n=3$. Statistical analysis was performed by one-way ANOVA. The level of significance was taken as $p \leqslant 0.05$.

physiological environment, in vivo targeting was investigated in this study. The distribution of these green fluorescent nanoparticles via aerosol delivery to the lung was examined under an in vivo image system (Xenogen IVIS $^{\circledR}$ Imaging System 50). Tissue autofluorescent subtraction using narrow band emission filters can diminish the background interference and improve detection sensitivity. The images of whole lung were demonstrated in Fig. 8. After exposure for $0.5 \mathrm{~h}$, mice with lung cancer showed higher fluorescence intensity than that of the control group; also a similar tendency was seen at $24 \mathrm{~h}$ after aerosol treatment (Fig. 8(a) and (b)). This indicated that an additional amount of GP-Av-bEGF was accumulated in cancerous lung via EGFR targeting; the in vivo targeting ability of EGF-modified nanoparticles (GP-Av-bEGF) was proved here.

\section{Discussion}

In recent years, biodegradable GPs have attracted considerable attention as potential drug-delivery vehicles for applications in controlled release [18]. GPs encapsulated with hydrophilic/hydrophobic drugs to act as drug carriers or as vectors of DNA in gene therapy have been developed in the past few years $[11,19,20]$. A previous study also indicated that gelatin microspheres could increase drug absorption in the respiratory tract [21]; therefore, in this study, we used gelatin as a carrier for pulmonary delivery.

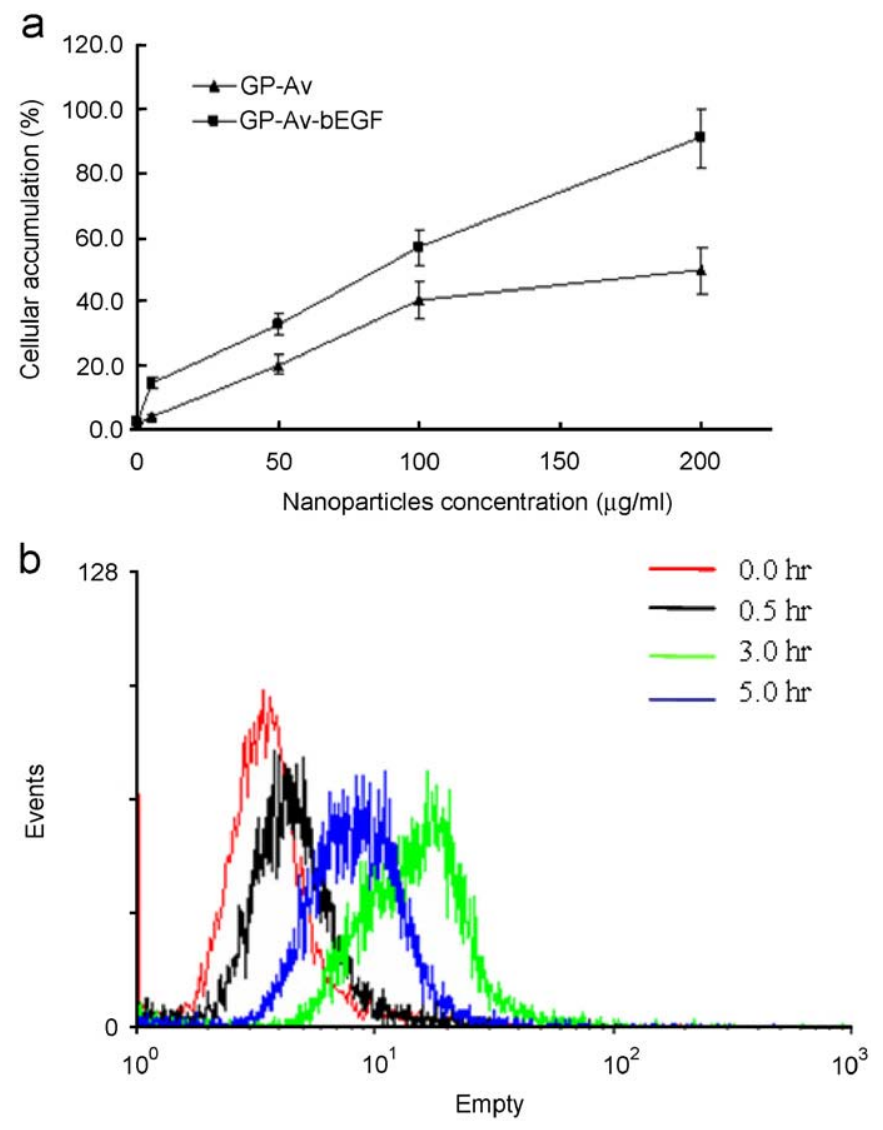

Fig. 5. (a) Influence of particle concentration ranging from 5.0 to $200 \mu \mathrm{g} /$ $\mathrm{ml}$ on cellular binding. A549 cells were incubated with GP-Av and $\mathrm{GP}-\mathrm{Av}-\mathrm{bEGF}$ for $3 \mathrm{~h}$ at $37^{\circ} \mathrm{C}$. The percentage of cells with nanoparticles binding was demonstrated. (b) The fluorescent intensity of cells was increased with time. (The concentration of GP-Av-bEGF is $100 \mu \mathrm{g} / \mathrm{ml}$.) The values represent mean $\pm \mathrm{SE}, n=3$.

After GPs are modified with NeutrAvidin ${ }^{\mathrm{FITC}}$-biotinylated EGF, their mean particle size reaches about $240 \mathrm{~nm}$ (Table 1). Some of the larger particles were sieved in the filtration membrane during the separation process, resulting in the homogeneous dispersion of GP-Av and GP-AvbEGF nanoparticles in the defined distribution range (Fig. 2(a)). The core-shell structure was clearly observed in Fig. 2(c), in which the condensed gelatin molecular-forming particles were embedded inside and EGF ligands were grafted onto the outer surface (Fig. 2(b)).

It is suggested that particles with longer circulation times should be $100 \mathrm{~nm}$ or less in diameter and have a hydrophilic surface in order to reduce the possibility of 


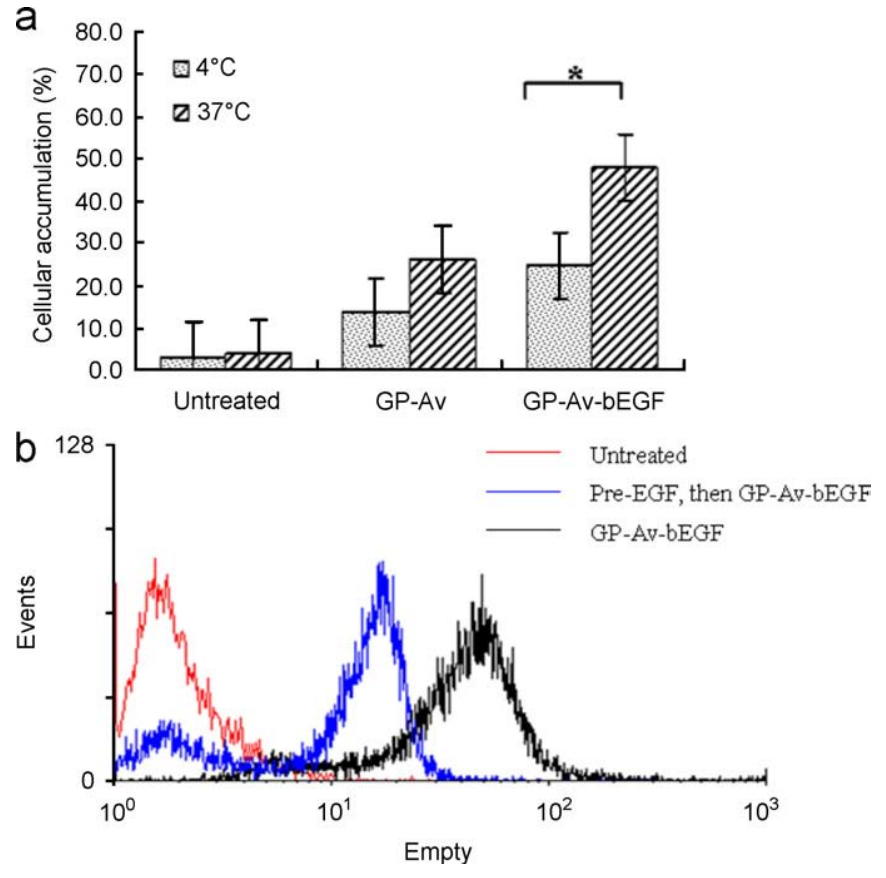

Fig. 6. (a) Data collected by flow cytometer show that incubation with $\mathrm{GP}-\mathrm{Av}-\mathrm{bEGF}$ nanoparticles at $37^{\circ} \mathrm{C}$ produces an increased $\mathrm{FL} 1$ signal in A549 cells in all tested particles $(100 \mu \mathrm{g} / \mathrm{ml})$. This affects all acquired cells and the extent of this shift was temperature dependent. The values represent mean $\pm \mathrm{SE}, n=3$. (b) Pre-EGF treated cells could inhibit the uptake of GP-Av-bEGF. Statistical analysis was performed by one-way ANOVA. The level of significance was taken as $p \leqslant 0.05$.

clearance by macrophages during the intravenous delivery process [22]. In our system, the size of GP-Av-bEGF is comparable with long-circulating liposomes, which has been proved with the effective pore size of most human tumors ranging from 200 to $600 \mathrm{~nm}$ in diameter [23,24]. Although the size of our hydrophilic carriers is greater than this criterion, this could be overcome by substituting inhalation delivery instead of intravenous for use in lung cancer treatment.

The result of zeta potential measurement is summarized in Table 1. The values of these samples were slightly negative, because the electrical charge of gelatin type A was positive at $\mathrm{pH} 4-6$, consistent with the previous results of Vandervoort et al. [11]. In the present study, we used NeutrAvidin instead of avidin and streptavidin. NeutrAvidin, a deglycosylated form of avidin with near-neutral $\mathrm{pI}$ (6.3), generated lower non-specific binding than avidin and streptavidin, and had no influence on the biotin-binding affinity [25]. After being modified with NeutrAvidin ${ }^{\text {FITC }}$, the zeta potential of GP-Av was similar to that of GP. Finally, when GP-Av nanoparticles were conjugated with bEGF, our data showed a slight increase (from -9.4 to $-8.5 \mathrm{mV}$ ) but no significant difference.

Cell viability can be determined by MTT proliferation assays. The cytotoxicity of GP-Av and GP-Av-bEGF nanoparticles was very low on human lung normal fibroblast cells (HFL1) since no decrease in cell viability was observed (Fig. 3). From different concentration and time variant experiments, we found that GPs did not affect cell viability. The result was supported by the previous studies [26], which indicated that GPs had no influence on the adhesion, morphology and cytoskeleton organization of human fibroblasts, and could be endocytosed by the fibroblasts without being toxic to cells even at high concentrations.

Overexpression of EGFR is a hallmark of numerous cancers and has become a major target for drug delivery and therapy. In the past 15 years, different approaches have been developed to block EGFR activation on cancer cells including various anti-EGFR-blocking monoclonal antibodies, recombinant proteins containing EGF fusion to toxins, and tyrosine kinase inhibitors [27]. Monoclonal antibodies (MAbs) are the most frequently used targeting agents conjugated to toxin moieties [27]. In this study, however, EGF was used as the targeting molecule. There may be advantages of using EGF instead of MAbs as targeting ligands for use in combination with drug delivery. Specific uptake is dependent on receptor-mediated endocytosis of the drug carrier. Both EGF and EGFR antibodies are taken up by ligand-induced receptormediated internalization, but the internalization rate may differ [28]. EGF-mediated endocytosis in A-431 cells was found to be faster than endocytosis mediated by two EGFR-targeting antibodies, 225 and 528 [28]. In addition, EGF stimulates endocytosis of the ligand-toxin complex EGF-saporin that could increase the drug concentration in the cytoplasma [29]. One important obstacle in the conjugation of nanoparticles is steric hindrance. However, the molecular weight of anti-EGFR MAb $(170 \mathrm{kDa})$ was larger than that of EGF $(6.2 \mathrm{kDa})$; the smaller ligand shows superiority compared to antibodies, which often fail in target binding due to steric hindrance [30]. Due to the larger size and binding affinity, anti-EGFR has more limited diffusion in the tissue and may be regarded as unsuitable for the treatment of solid tumors [31]. Therefore, EGF was more favored than anti-EGFR MAb in nanoparticle conjugation in this study.

Whether EGF-targeted colloidal drug carrier would enter tumor cells is dependent on the surface density of EGFR as well as its receptor internalization [32]. Therefore, cell lines with different expression levels of EGFR were used for the evaluation of nanoparticle uptake (Table 2). EGFR expression on A549 (92.4\%) and H520 $(2.1 \%)$ from FACS analysis was comparable with other research studies [33]. The cell uptake rate of GP-Av-bEGF was also proportional to EGFR amount on the cell surface (Fig. 4). During the same culture period, the group of GP-Av-bEGF particles revealed more fluorescences in the cells compared with the GP-Av group, probably due to the receptor-mediated endocytosis pathway (Fig. 5(a)). Receptor-mediated endocytosis is an essential first step for many antibody-targeted therapies [34]. The biotinylation of EGF was formed by Sulfo-NHS-LC-biotin to conjugate EGF via the amino group and not the carboxyl group. Removal of the $\mathrm{COOH}$ terminal polypeptide has been shown to 

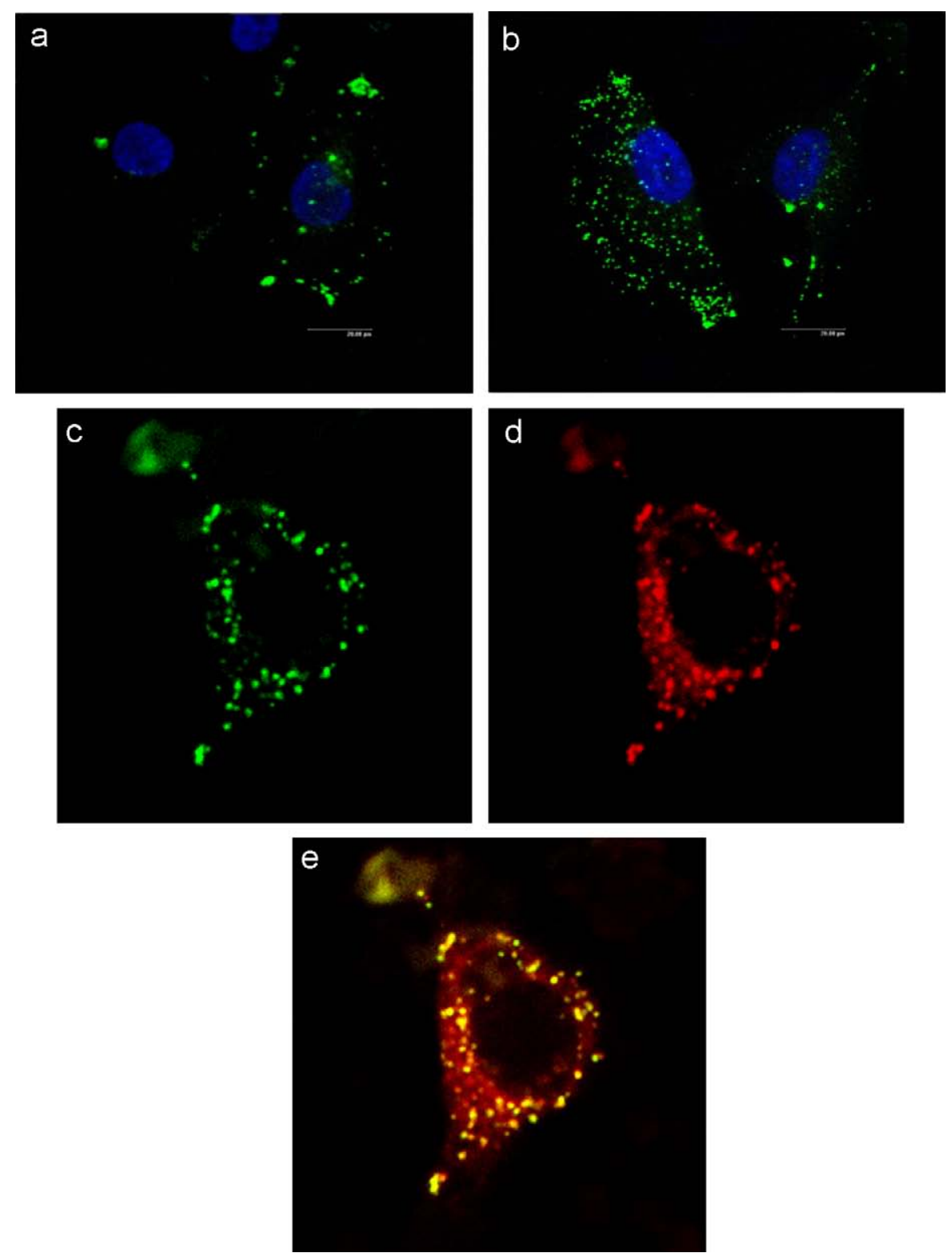

Fig. 7. Lung adenocarcinoma cells (A549) were treated with gelatin nanoparticles (with or without EGF modified) for $3 \mathrm{~h}$ in $100 \mu \mathrm{g} / \mathrm{ml}$ and then processed for confocal microscopic examination: (a) cells incubated with GP-Av and (b) cells treated by GP-Av-bEGF. Intracellular track for cells treated with EGF modified particles: (c) GP-Av-bEGF nanoparticles (green label), (d) lysosomal staining showed in red, (e) yellow for co-localization of (c) and (d). Gelatin nanoparticles were shown in green color by FITC. Cell nucleus was stained with DAPI and appeared in blue. LysoTracker Red was used to label lysosome in red color.

dramatically reduce the affinity of EGF for its receptor [35]; our data showed that GP-Av-bEGF still possessed targeting ability via the previous modification on the amino groups of EGF.

Lower extent is taken up by unspecific endocytosis; unspecific uptake of GP-Av-bEGF in normal cells could therefore be a potential limitation causing unspecific toxicity (Fig. 4). Of the two energy-dependent endocytotic pathways, receptor-mediated endocytosis is initiated by ligand binding to specific cell membrane receptors, whereas adsorption endocytosis is preceded by non-specific interaction of the ligand with the cell membrane [17]. The result of flow cytometric analysis showed that incubation with fluorescence-labelled nanoparticles at $37^{\circ} \mathrm{C}$ produced a higher FL1 signal in A549 cells than that at $4{ }^{\circ} \mathrm{C}$ (Fig. 6(a)). Temperature dependency of nanoparticle uptake suggests that the incorporation of nanoparticles is not a passive diffusion process through the cellular membrane, but an active, endocytosis-like process.

The uptake amount of particles was observed in the presence of pre-EGF incubation (Fig. 6(b)). Because of competitive receptor binding between free EGF (pre-addition) and GP-Av-bEGF nanoparticles, this result is in agreement with the study of Lee [36]; free EGF would significantly reduce the transfection rate of EGF-modified vector. Pre-occupied receptors with free EGF significantly 


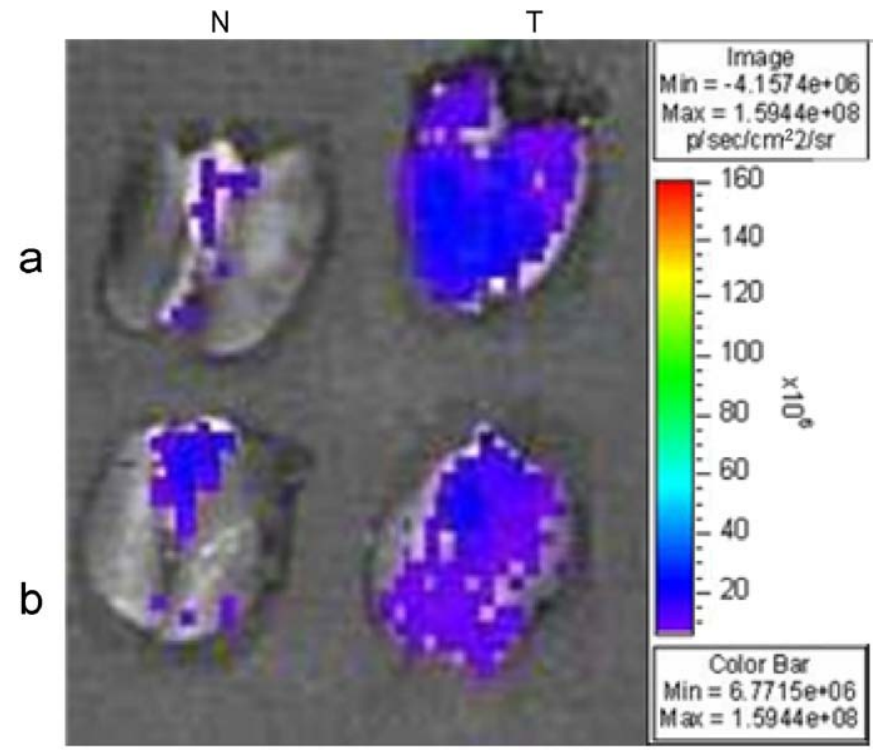

Fig. 8. Fluorescent image of lung. The sites of color spot on the tissue were initiated by green fluoresce from FITC on the gelatin nanoparticles (GP-Av-bEGF). The cancerous lung had much higher fluorescent spots on it: (a) the result of $0.5 \mathrm{~h}$ after inhalation and (b) the image obtained $24 \mathrm{~h}$ later. (N: normal SCID mice; T: tumor inoculation by A549 cells in SCID mice)

reduced the number of available surface-exposed EGF receptors by the down-regulation effect of EGF [37], resulting in lowering the extent of specific cellular uptake of the complex.

Conventional drug administrations are usually through oral or intravenous injections. Drug delivery via aspiration has its advantages. There are several advantages in delivering drugs via aerosols, which may be the most efficient and non-invasive means of delivery drugs to the lung tissue; for example, it can reach large surface areas and avoid the risks associated with other systemic administration methods [38]. Nadezhda [16] showed that paclitaxel liposome aerosol treatment induced inhibition of pulmonary metastases and led to prolonged survival in mice. The results of the study demonstrated the therapeutic potential of aerosol technology in lung cancer therapy. In our study, a nebulizer was adapted to produce droplets of about $1-3 \mu \mathrm{m}$, which generally avoid oropharyngeal deposition and give sufficient deposition in the lung [39]. By using this technique, the nanoparticles not only attached to the outer surface of the tumor cells but also internalized into A549 cells (Fig. 8). We also proved that in cancerous lung tissue, GP-Av-bEGF delivered by inhalation resulted in satisfactory deposition efficiency. From the opinion of Yip et al. [31], lower affinity of EGF to EGFR is easier for tissue diffusion in solid tumors. Encapsulated anti-cancer drugs in our GP-Av-bEGF nanoparticles directly delivered by inhalation manner to lung tissue would thus have great potential to provide a treatment method to cure lung cancer, and was investigated in our studies.

\section{Conclusion}

In conclusion, biotinylated EGF and NeutrAvidin ${ }^{\text {FITC }}$ have been covalently grafted to GPs for specific targeting to lung cancer cells. The particle size of GP-Av-bEGF was about $240 \mathrm{~nm}$ in the form of a core-shell structure and these carriers were non-toxic for normal cells (HFL1). The uptake rate of GP-Av-bEGF was dependent on incubation time as well as temperature, particle concentration and EGFR quantity on cells. The entrance efficiency of GP-Av-bEGF in lung adenocarcinoma cells (A549) was obviously increased when compared to that in the normal fibroblast cells (HFL1) and lung squamous cells (H520) due to higher amount of EGFR on A549. In vitro culture of GP-Av-bEGF particles with A549 cells demonstrated that uptake of nanoparticles was effected by EGF receptormediated endocytosis. GP-Av-bEGF nanoparticles were delivered by inhalation to the lung of SCID mice and revealed that cancerous lung had higher fluoresced accumulation. It is suggested that GPs modified with NeutrAvidin ${ }^{\text {FITC }}$-biotinylated EGF can specifically target lung cancer cells ex vivo and still have tracking ability in the complicated physiological environment. Further studies of encapsulated anti-cancer drugs in our GP-Av-bEGF nanoparticles will be investigated in the near future.

\section{References}

[1] Kerr KM. Pulmonary preinvasive neoplasia. J Clin Pathol 2001;54: 257-71

[2] Mitra S, Gaur U, Ghosh PC, Maitra AN. Tumour targeted delivery of encapsulated dextran-doxorubicin conjugate using chitosan nanoparticles as carrier. J Control Release 2001;74:317-23.

[3] He X, Lin X, Wang K, Chen L, Wu P, Yuan Y, et al. Biocompatible core-shell nanoparticles for biomedicine. In: Nalwa HS, editor. Encyclopedia of nanoscience and nanotechnology. Steveson Ranch: American Scientific Publishers; 2004. p. 235-53.

[4] Yokoyama M. Drug targeting with nano-sized carrier systems. J Artif Organs 2005;8:77-84.

[5] Leserman LD, Barbet J, Kourilsky F, Weinstein JN. Targeting to cells of fluorescent liposomes covalently coupled with monoclonal antibody or protein A. Nature 1980;288:602-4.

[6] Dinauer N, Balthasar S, Weber C, Kreuter J, Langer K, Briesena HV. Selective targeting of antibody-conjugated nanoparticles to leukemic cells and primary T-lymphocytes. Biomaterials 2005;26:5898-906.

[7] Yamada T, Iwasaki Y, Tada H, Iwabuki H, Chuah MK, VandenDriessche T, et al. Nanoparticles for the delivery of genes and drugs to human hepatocytes. Nat Biotechnol 2003;21:885-90.

[8] Sledge Jr GW, Miller KD. Exploiting the hallmarks of cancer: the future conquest of breast cancer. Eur J Cancer 2003;39:1668-75.

[9] Kullberg EB, Bergstrand N, Carlsson J, Edwards K, Johnsson M, Sjoerberg S, et al. Development of EGF-conjugated liposomes for targeted delivery of boronated DNA-binding agents. Bioconjugate Chem 2002;13:737-43.

[10] Rusch V, Klimstra D, Venkatraman E, Pisters PWT, Langenfeid J, Dmitrovsky E. Overexpression of the epidermal growth factor receptor and its ligand transforming growth factor alpha is frequent in resectable non-small cell lung cancer but does not predict tumor progression. Clin Cancer Res 1997;3:515-22.

[11] Vandervoort J, Ludwig A. Preparation and evaluation of drugloaded gelatin nanoparticles for topical ophthalmic use. Eur J Pharm Biopharm 2004;57:251-61. 
[12] Coester C, Kreuter J, Briesen HV, Langer K. Preparation of avidinlabelled gelatin nanoparticles as carriers for biotinylated peptide nucleic acid (PNA). Int J Pharm 2000;196:147-9.

[13] Green NM. Avidin. Biochem J 1963;89:585-91.

[14] Hermanson GT. Bioconjugate techniques. San Diego: Academic Press; 1996.

[15] Coester CJ, Langer K, Briesen HV, Kreuter J. Gelatin nanoparticles by two step desolvation - a new preparation method, surface modifications and cell uptake. J Microencapsul 2000;17(2):187-93.

[16] Koshkina NV, Waldrep JC, Roberts LE, Golunski E, Melton S, Knight V. Paclitaxel liposome aerosol treatment induces inhibition of pulmonary metastases in murine renal carcinoma model. Clin Cancer Res 2001;7:3258-62.

[17] Huang M, Ma Z, Khor E, Lim LY. Uptake of FITC-chitosan nanoparticles by A549 cells. Pharm Res 2002;19:1488-94.

[18] Young S, Wong M, Tabata Y, Mikos AG. Gelatin as a delivery vehicle for the controlled release of bioactive molecules. J Control Release 2005;109:256-74.

[19] Leo E, Vandelli MA, Cameroni R, Flavio F. Doxorubicin-loaded gelatin nanoparticles stabilized by glutaraldehyde: involvement of the drug in the cross-linking. Int J Pharm 1997;155:75-82.

[20] Truong-Le VL, Walsh SM, Schweibert E, Mao H-Q, Guggino WB, August JT, et al. Gene transfer by DNA-gelatin nanospheres. Arch Biochem Biophys 1999;361(1):47-56.

[21] Morimoto K, Katsumata H, Yabuta T, Iwanaga K, Kakemi M, Tabata $\mathrm{Y}$, et al. Gelatin microspheres as a pulmonary delivery system: evaluation of salmon calcitonin absorption. J Pharm Pharmacol 2000;52:611-7.

[22] Brannon-Peppas L, Blanchette JO. Nanoparticle and targeted systems for cancer therapy. Adv Drug Deliv Rev 2004;56:1649-59.

[23] Jain RK. Delivery of molecular and cellular medicine to solid tumors. Adv Drug Deliv Rev 2001;46:149-68.

[24] Jain RK. Normalizing tumor vasculature with anti-angiogenic therapy: a new paradigm for combination therapy. Nat Med 2001;7:987-9.

[25] Gorostiza P, Tombola F, Verdaguer A, Smith SB, Bustamante C, Isacoff EY. Molecular handles for the mechanical manipulation of single-membrane proteins in living cells. IEEE Trans Nanobiosci 2005;4:269-76.

[26] Gupta AK, Gupta M, Yarwood SJ, Curtis ASG. Effect of cellular uptake of gelatin nanoparticles on adhesion, morphology and cytoskeleton organisation of human fibroblasts. J Control Release 2004;95:197-207.

[27] Ciardiello F. Epidermal growth factor receptor tyrosine kinase inhibitors as anticancer agents. Drugs 2000;60(Suppl 1):25-32.
[28] Fan Z, Lu Y, Wu X, Mendelsohn J. Antibody-induced epidermal growth factor receptor dimerization mediates inhibition of autocrine proliferationof A431 squamous carcinoma cells. J Biol Chem 1994; 269(44):27595-602.

[29] Weyergang A, Selbo PK, Berg K. Photochemically stimulated drug delivery increases the cytotoxicity and specificity of EGF-saporin. J Control Release 2006;111:165-73.

[30] Proske D, Michael B, Buhmann R, Resch A. Aptamers-basic research, drug development, and clinical applications. Appl Microbiol Biotechnol 2005;69:367-74.

[31] Yip WL, Weyergang A, Berg K, Tonnesen HH, Selbo PK. Targeted delivery and enhanced cytotoxicity of Cetuximab-Saporin by photochemical internalization in EGFR-positive cancer cells. Molecular Pharmaceutics 2007;4:241-51.

[32] Kirpotin DPJ, Hong K, Zalipsky S, Li WL, Carter P, Benz CC, et al. Sterically stabilized anti-HER2 immunoliposomes: Design and targeting to human breast cancer cells in vitro. Biochemistry 1997;36: 66-75.

[33] Raben D, Helfrich B, Chan DC, Ciardiello F, Zhao L, Franklin W, et al. The effects of Cetuximab alone and in combination with radiation and/or chemotherapy in lung cancer. Clin Cancer Res 2005;11: 795-805.

[34] Nielsen UB, Kirpotin DB, Pickering EM, Hong K, Park JW, Shalaby MR, et al. Therapeutic efficacy of anti-ErbB2 immunoliposomes targeted by a phage antibody selected for cellular endocytosis. Biochim Biophys Acta 2002;1591:109-18.

[35] Planck SR, Finch JS, Magun BE. Intracellular processing of epidermal growth factor II, intracellular cleavage of the $\mathrm{COOH}$ terminal region of 125I-epidermal growth factor. J Biol Chem 1984; 259(5):3053-7.

[36] Lee H, Kim TH, Park TG. A receptor-mediated gene delivery system using streptavidin and biotin-derivatized, pegylated epidermal growth factor. J Control Release 2002;83:109-19.

[37] Krupp MN, Connolly DT, Lane MD. Synthesis, turnover and downregulation of epidermal growth factor receptors in human A431 epidermal carcinoma cells and skin fibroblasts. J Biol Chem 1982;257: $11489-96$.

[38] Kim HW, Park IK, Cho CS, Lee KH, George R, Beck J, et al. Aerosol delivery of glucosylated polyethylenimine/phosphatase and tensin homologue deleted on chromosome 10 complex suppresses akt downstream pathways in the lung of k-ras null mice. Cancer Res 2004;64:7971-6.

[39] Cryan SA. Carrier-based strategies for targeting protein and peptide drugs to the lungs. AAPS J 2005;7:20-41. 